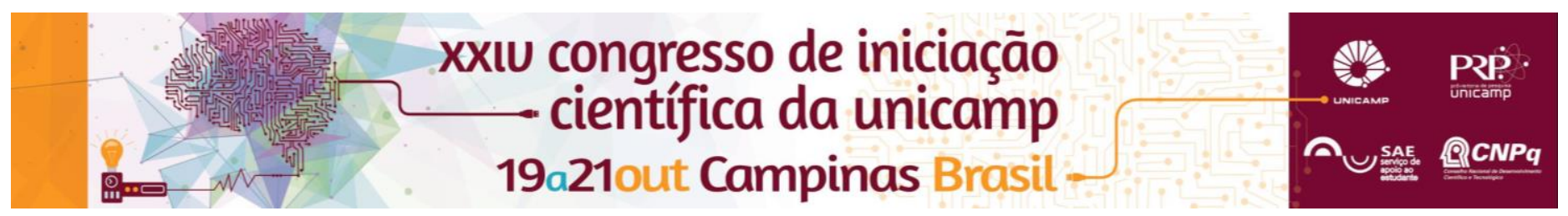

\title{
Influência do polimorfismo MCC c.*5077A>G, relacionado ao ciclo celular, no risco e prognóstico do carcinoma de células escamosas de laringe
}

\author{
Ricardo A. A. dos Santos, Bruno L. França, Carlos T. Chone, Gustavo J. Lourenço, Carmen S. P. Lima.
}

\section{Resumo}

O carcinoma de células escamosas de laringe (CCEL) é um tumor maligno de mal prognóstico. O polimorfismo MCC c. ${ }^{\star} 5077 \mathrm{~A}>\mathrm{G}$ (rs7033) está envolvido com o risco para outros carcinomas de cabeça e pescoço. Já é conhecido que o genótipo MCC AA deste polimorfismo está associado a risco aumentado de CCEL, especialmente se analisado junto à variável cor de pele. O objetivo deste estudo foi avaliar se o polimorfismo citado altera também o prognóstico de pacientes com CCEL. A sobrevida global dos pacientes foi considerada como indicador de prognóstico. Não há resultados preliminares, no entanto, esperamos que um resultado positivo reforce a necessidade de tratamento diferenciado para genótipos mais agressivos.

\section{Palavras-chave:}

Carcinoma de células escamosas de laringe, MCC, sobrevida global.

\section{Introdução}

O carcinoma de células escamosas de laringe (CCEL) é um tumor maligno que pode evoluir com rápida disseminação e morte do paciente. O polimorfismo MCC c. ${ }^{\star} 5077 \mathrm{~A}>\mathrm{G}$ (rs7033) está envolvido com o risco para outros carcinomas de cabeça e pescoço [1]. No entanto, seu papel no CCEL ainda é desconhecido, o que justifica - estudo das alterações que o polimorfismo pode provocar no risco e prognóstico do tumor. Estudo recente de nosso laboratório indicou que o polimorfismo MCC c. ${ }^{*} 5077 \mathrm{~A}>\mathrm{G}$ (rs7033) altera o risco para o CCEL: indivíduos MCC AA, homozigoto selvagem, estiveram sob risco 2,3 (IC 95\%: 1,01-5,04) vezes maior de ocorrência de CCEL do que os portadores dos demais genótipos; além disso, indivíduos brancos com genótipo MCC AA estiveram sob risco 2,9 (IC 95\%: 1,13-7,32) vezes maior de CCEL que aqueles com outros genótipos. Considerando o dado de risco já obtido, o objetivo deste estudo foi avaliar, na mesma amostra do estudo indicado, se o genótipo do gene MCC altera o prognóstico de pacientes com CCEL.

\section{Resultados e Discussão}

Os pacientes foram classificados de acordo com sexo, idade, cor de pele, tabagismo, etilismo, sítio e local do tumor, estagiamento, grau histopatológico, tipo de tratamento, ocorrência de recidiva e genótipo do gene MCC c. ${ }^{*} 5077 \mathrm{~A}>\mathrm{G}$ (rs7033). A data de diagnóstico do CCEL e data de óbito do paciente foram utilizadas para determinar a sobrevida global (SG), indicador de prognóstico eleito para este estudo. Considerou-se a SG como o período entre o diagnóstico e a morte por qualquer causa ou perda de seguimento. As informações de cada paciente ainda serão submetidas à avaliação estatística, por isso não apresentamos resultados neste documento. A SG será calculada por meio da curva de probabilidade estimada de Kaplan-Meier e a diferença entre curvas pelo teste do log-rank. A significância dessas diferenças será também avaliada em análise univariada de Cox. Em um segundo tempo, todas as variáveis com $P \leq 0,10$ serão incluídas na análise multivariada de Cox. O nível de significância adotado para os testes estatísticos será de $5 \%(P<0,05)$.

\section{Resultados esperados}

Considerando a relevância assumida pelo polimorfismo MCC c. ${ }^{\star} 5077 \mathrm{~A}>\mathrm{G}$ (rs7033) para o risco de CCEL e outros carcinomas de cabeça e pescoço, esperamos que os resultados apresentem influência do genótipo do gene MCC sobre a história natural do CCEL, de modo a alterar o prognóstico desta doença. Entendemos que, com este dado, protocolos de tratamento mais ou menos agressivos possam ser aplicados de acordo com o moderno conceito de terapêutica personalizada do câncer.

\section{Agradecimentos}

Agradeço à orientação da Profa. Dra. Carmen Silvia Passos Lima e ao Dr. Gustavo Jacob Lourenço por todo 0 apoio. $\mathrm{O}$ trabalho foi desenvolvido com o financiamento do Conselho Nacional de Pesquisa (CNPq), programa PIBIC.

\footnotetext{
1 LOURENÇO GJ. Identificação de genes de suscetibilidade herdada para o carcinoma de células escamosas de base de língua por genotipagem em larga escala. Tese (Doutorado), Universidade Estadual de Campinas, Faculdade de Ciências Médicas, 2011.
} 